\title{
Identification of Patients with Advanced Fibrosis Due to Nonalcoholic Fatty Liver Disease: Considerations for Best Practice
}

\author{
Salvador Augustin ${ }^{1}$, Aijaz Ahmed ${ }^{2}$, Naim Alkhouri ${ }^{3}$, Ali Canbay ${ }^{4}$, Lynsey Corless ${ }^{5}$, Atsushi Nakajima ${ }^{6}$, Takeshi Okanoue ${ }^{7}$, \\ Salvatore Petta ${ }^{8}$, Vlad Ratziu ${ }^{9}$, Emmanuel A. Tsochatzis ${ }^{10}$, Vincent Wai-Sun Wong ${ }^{11,12}$, Manuel Romero-Gómez ${ }^{13}$
}

1) Liver Unit Hospital Univ. Vall d'Hebron, Vall d'Hebron Research Inst., Univ. Autònoma de Barcelona, Spain; 2) Div. of Gastroenterol. and Hepatol, Stanford Univ. School of Medicine, Stanford, California, USA; 3) Texas Liver Institute, Univ. Texas Health Science Center at San Antonio, San Antonio, Texas, USA; 4) Dept. of Gastroenterol, Hepatol. and Infectious Dis, Univ. Magdeburg, Magdeburg, Germany; 5) Hull University Teaching Hospitals NHS Trust, Univ. of Hull, Hull, UK; 6) Dept. of Gastroenterol and Hepatol, Yokohama City Univ. Graduate School of Medicine, Yokohama, Japan; 7) Dept. Gastroenterol \& Hepatol, Saiseikai Suita Hospital, Suita, Japan; 8) Section of Gastroenterol and Hepatol, PROMISE, Univ. Palermo, Palermo, Italy; 9) Inst. for Cardiometabolism and Nutrition, Sorbonne Univ., Hospital Pitié Salpêtrière, Paris, France; 10) UCL Inst. for Liver and Digestive Health, Royal Free Hospital, London, UK; 11) Dept. Medicine and Therapeutics, The Chinese University of Hong Kong, Hong Kong; 12) State Key Laboratory of Digestive Disease, The Chinese University of Hong Kong, Hong Kong; 13) UCM Dig. Dis, Virgen del Rocío Univ. Hospital, Unive. Seville, Seville, Spain

\section{Address for correspondence: Manuel Romero-Gómez UCM Dig. Dis., Virgen del Rocío Univ. Hospital, Univ. Seville, Seville, Spain \\ mromerogomez@us.es}

\section{ABSTRACT}

Nonalcoholic fatty liver disease (NAFLD) and nonalcoholic steatohepatitis (NASH) prevalence has increased in the past two decades, resulting in a significant but under-recognised public health burden. This impacts the prevalence of advanced fibrosis, end-stage liver disease and associated extrahepatic manifestations. To understand the challenges in recognising patients with advanced fibrosis due to NASH and develop a standardised approach to screen these patients, the authors of this document provided their opinions and expertise from practice and published evidence to identify key challenges and current approaches for diagnosing NASH. The severity of liver fibrosis due to NASH is the main indicator of associated morbidity and mortality outcomes. Therefore, identifying patients with, or at risk of, advanced fibrosis due to NASH and linking them to appropriate care is critical. This can be challenging due to a lack of awareness of NASH among healthcare professionals and a lack of standardised protocols for identifying patients. Simple noninvasive tests may provide an opportunity to facilitate early identification of these patients. This article proposes a simple, universally applicable diagnostic algorithm for use in clinical practice, that includes sequential use of noninvasive tests, ideally a biological marker and an imaging technique, which may help to facilitate early diagnosis of these patients. In the opinion of the authors, early detection of advanced fibrosis is fundamental in the efforts to halt the progression of NASH and diagnostic algorithms may facilitate pre-emptive interventions to curtail the disease.

Key words: advanced fibrosis - best practice - identification - NAFLD - NASH.

Abbreviations: ALT: alanine aminotransferase; AST: aspartate aminotransferase; APRI: the AST-to-platelet ratio index; ARFI: acoustic radiation force impulse; DeMILI ${ }^{\circledR}$ : Detection of Metabolic-Induced Liver Injury; ELF: Enhanced Liver Fibrosis test; FIB-4: fibrosis-4 score; HCC: hepatocellular carcinoma; HCP: healthcare professional; NAFLD: nonalcoholic fatty liver disease; NASH: nonalcoholic steatohepatitis; NFS: NAFLD fibrosis score; NIT: noninvasive test; SWE: shear wave elastography; T2DM: type 2 diabetes mellitus.

\section{EPIDEMIOLOGY AND DISEASE BURDEN}

Chronic liver disease is a significant public health issue, affecting approximately 844 million people worldwide and accounting for 2 million deaths annually [1]. In recent years, nonalcoholic fatty liver disease (NAFLD) has surpassed viral hepatitis as the most common aetiology of chronic liver disease [1-3].

Approximately $25 \%$ of the global population have NAFLD [4], of whom $25 \%$ will develop nonalcoholic steatohepatitis (NASH), the progressive form of the disease [5]. A modelling study suggests that by 2030, the prevalence of NASH will rise by up to $56 \%$, with liver mortality and advanced liver disease expected to more than double [6].

The rapid increase in NAFLD/NASH has already impacted on the incidence of late-stage liver disease. In the USA, the rate of NAFLD-associated advanced fibrosis and NASH cirrhosis has increased by more than 2-fold over the past two decades [7]; in many European countries, NASH mortality is projected to double in the next two decades [6]. NASH is currently the second leading indication for liver transplantation and liver transplantation waitlist registration in the USA [8], and the most rapidly growing cause of hepatocellular carcinoma (HCC) among USA patients listed for liver transplantation [9]. In the UK, NAFLD patients present with larger tumours that are less likely to be amenable to curative therapy compared with patients with viral hepatitis $C[10]$. Therefore, there is an urgent need to address the already significant impact of NASH, particularly as the annual direct NAFLD-associated medical costs are estimated to be around \$103 billion in the USA, and $€ 35$ billion in Europe [11]. 
The presence and severity of NASH is associated with type 2 diabetes mellitus (T2DM), as well as a greater prevalence and incidence of cardiovascular disease and chronic kidney disease; it may also be a risk factor for colorectal neoplasia $[12,13]$. Patients with T2DM are particularly susceptible to more severe forms of NAFLD and its associated consequences $[14,15]$ as they have a higher prevalence of advanced fibrosis compared with the general population [16]; approximately $10 \%$ of people with T2DM have advanced liver disease [15]. These associations imply that identifying patients with NASH would allow for increased surveillance and potentially earlier intervention to reduce the risk of hepatic, cardiovascular and renal complications.

\section{THE IMPORTANCE OF IDENTIFYING PATIENTS WITH ADVANCED FIBROSIS DUE TO NAFLD/NASH}

In patients with NASH, analyses of sequential liverbiopsy specimens indicate that fibrosis progresses at a rate of approximately one stage every 7 years, suggesting that moderate fibrosis (fibrosis stage [F]2) progresses to cirrhosis (F4) within 20 years [5]. However, a number of studies have indicated that the rate of progression varies widely [17-19]. Detecting fibrosis in patients with NASH is critical as the degree of fibrosis independently predicts the development of liver-related complications, the need for liver transplantation, and liver-related and overall mortality in patients with NAFLD [20-22]. Degree of fibrosis is also associated with a higher incidence of chronic kidney disease and increased cardiovascular disease-related mortality [23]. Nevertheless, despite its high prevalence and the potential consequences of inaction, studies suggest that NAFLD/NASH is largely underrecognised [24-26]. Therefore, there is a pressing need to identify patients with advanced fibrosis and cirrhosis, so that they can be managed to delay further progression, especially given the large number of patients with undiagnosed cirrhosis within the general population (6-7\%) [27].

\section{Key summary points:}

- There is an urgent need to address and manage NASH as the associated clinical and economic burden is predicted to double in the next decade. - In the authors' opinion, healthcare professionals (HCPs) should be more proactive in identifying patients with advanced fibrosis due to NASH, as fibrosis stage is a predictor for hepatic and extrahepatic morbidity and mortality.

- This is particularly important due to the significant prevalence of silent cirrhosis in the general population, specifically in patients with T2DM.

\section{THE CHALLENGE OF IDENTIFYING PATIENTS WITH ADVANCED FIBROSIS DUE TO NAFLD/NASH}

Identifying individuals with advanced fibrosis due to NAFLD/NASH allows for management strategies to be put in place, which may improve patient outcomes and potentially reduce future healthcare burdens. However, there is a general lack of awareness of NAFLD/NASH among HCPs, particularly in primary care and non-liver specialists such as endocrinologists [28-30]. The accompanying lack of awareness of treatments in clinical development for NASH [28] may also lead to a lack of motivation to identify at-risk patients, and a belief that the associated comorbidities of NASH are the responsibilities of other specialists.

Lack of awareness among HCPs is compounded by a lack of standardisation within the guidelines. Whilst some national and international guidelines support screening of high-risk populations for NAFLD/NASH, there is a lack of consensus regarding the value of screening individuals. Guidelines predominantly cite uncertainties around diagnostic tests and treatment options, and a lack of real-world evidence supporting long-term benefits and cost-effectiveness of screening [31, 32]. While the authors do not advocate large national-scale efforts until cost-effectiveness data has been published, targeted initiatives to identify and refer patients with advanced fibrosis can address an unmet need.

The utility of liver biopsy, considered to be the 'gold standard' for diagnosing fibrosis in patients with NAFLD/ $\mathrm{NASH}$, is limited by cost, accuracy, risk of adverse events and invasiveness, making it unsuitable for large-scale screening [33-35]. Therefore, simple, easily accessible, validated noninvasive tests (NITs) are critical. This document will distil the performance reviews of these NITs into a simple, practical, universally applicable algorithm for use in a variety of clinical settings, to reduce the challenges associated with identifying high-risk patients with NASH.

\section{Key summary points}

- Consensus is lacking regarding the value of screening individuals for NAFLD/NASH due to uncertainties around diagnostic tests and treatment options, and a lack of evidence supporting the long-term benefits and costeffectiveness of screening.

- Due to the development of reliable NITs to identify patients with advanced fibrosis, there is now potential to put management strategies in place earlier.

\section{CONSIDERATIONS FOR IDENTIFYING PATIENTS WITH ADVANCED FIBROSIS DUE TO NAFLD/NASH}

Prior to designing a strategy to identify and manage patients with advanced fibrosis due to NASH, population demographics, healthcare systems and availability of techniques need to be considered.

\section{Which patient populations should be screened?}

NAFLD/NASH induce non-specific and generally prevalent symptoms [36, 37]; a large proportion of cases may be asymptomatic until patients develop decompensated cirrhosis [38-40]. Screening is therefore essential to ensure that patients, particularly those with advanced fibrosis (F3-F4), are identified and linked to care.

Current guidelines do not recommend widespread or community screening, mainly due to the perceived associated direct and indirect medical costs $[31,32,41]$. However, some national and international initiatives (ETHON project, Spain [42]; international LiverScreen project [NCT03789825]) are currently investigating the effectiveness of screening the general population for significant liver disease, considering evidence that this may be a cost-effective strategy. 
Table I. Guideline recommendations: screening for NAFLD fibrosis

\begin{tabular}{|c|c|c|}
\hline Guidelines & Recommendations & Recommended noninvasive tests \\
\hline AASLD [32] & $\begin{array}{l}\text { - Routine screening for NAFLD in high-risk groups attending } \\
\text { primary care, diabetes or obesity clinics is not advised at this } \\
\text { time because of uncertainties surrounding diagnostic tests } \\
\text { and treatment options, along with lack of knowledge related to } \\
\text { long-term benefits and cost-effectiveness of screening }\end{array}$ & $\begin{array}{l}\text { - NFS or FIB-4 index for identifying NAFLD patients with } \\
\text { higher likelihood of bridging fibrosis (F3) or cirrhosis (F4) } \\
\text { - VCTE or MRE for identifying advanced fibrosis in patients } \\
\text { with NAFLD }\end{array}$ \\
\hline EASL [31] & $\begin{array}{l}\text { - Patients with insulin resistance and/or metabolic risk factors } \\
\text { (i.e. obesity or MetS) should undergo diagnostic procedures } \\
\text { for the diagnosis of NAFLD } \\
\text { - All individuals with steatosis should be screened for features } \\
\text { of MetS, independent of liver enzymes. All individuals with } \\
\text { persistently abnormal liver enzymes should be screened for } \\
\text { NAFLD } \\
\text { - In subjects with obesity or metabolic syndrome, screening } \\
\text { for NAFLD by liver enzymes and/or ultrasound should be } \\
\text { part of a routine work-up. In high-risk individuals (age > } 50 \\
\text { years, T2DM, MetS) case finding of advanced disease (i.e. } \\
\text { NASH with fibrosis) is advisable }\end{array}$ & $\begin{array}{l}- \text { NFS, FIB-4, ELF, FibroTest for diagnosis of at-risk patients } \\
\text { with US-confirmed steatosis and normal liver enzymes and } \\
\text { monitoring of low-risk patients with steatosis }\end{array}$ \\
\hline $\begin{array}{l}\text { Asia-Pacific Working } \\
\text { Party [107] }\end{array}$ & $\begin{array}{l}\text { - Screening of NAFLD may be considered in at-risk groups } \\
\text { such as patients with T2DM and obesity }\end{array}$ & $\begin{array}{l}\text { - NFS, FIB-4, BARD score, ELF, FibroTest, FibroMeter, } \\
\text { HepaScore have shown reasonable diagnostic accuracy. } \\
\text { Concerns regarding definition of threshold values in Asian } \\
\text { patients: "at the present time, the clinical use of such tools to } \\
\text { avoid liver biopsy remains undefined" }\end{array}$ \\
\hline NICE [108] & $\begin{array}{l}\text { - Offer testing for advanced liver fibrosis to people with } \\
\text { NAFLD }\end{array}$ & • ELF \\
\hline WGO [41] & $\begin{array}{l}\text { - The diagnosis should be sought in all patients who present } \\
\text { with risk factors for NASH }\end{array}$ & $\begin{array}{l}\text { - None; insufficient data; costs; limited availability Recommends } \\
\text { liver biopsy }\end{array}$ \\
\hline $\begin{array}{l}\text { Japanese Society of } \\
\text { Gastroenterology } \\
\text { and Japanese Society } \\
\text { of Hepatology [109] }\end{array}$ & - Not specified & $\begin{array}{l}\text { - No practically useful surrogate markers for diagnosing NASH } \\
\text { NFS for predicting severity of fibrosis }\end{array}$ \\
\hline $\begin{array}{l}\text { Belgian Association } \\
\text { for the Study of the } \\
\text { Liver [110] }\end{array}$ & $\begin{array}{l}\text { - The following populations are at high risk for NAFLD } \\
\text { and should be screened by their general practitioner or the } \\
\text { specialists involved: presence of the metabolic syndrome or its } \\
\text { components, patients with obesity (BMI } \geq 30 \mathrm{~kg} / \mathrm{m} 2 \text { ), patients } \\
\text { with T2DM or patients with a history of ischemic CVD }\end{array}$ & $\begin{array}{l}\text { - FIB-4 and NFS with age-appropriate cut-offs and US-based } \\
\text { elastography are acceptable for identifying patients at low risk of } \\
\text { advanced fibrosis/cirrhosis } \\
\text { - Combine for increased accuracy } \\
\text { Other tests (e.g. ELF, FibroTest) can be used according to local } \\
\text { expertise, but are proprietary and not reimbursed }\end{array}$ \\
\hline $\begin{array}{l}\text { Italian Association } \\
\text { for the Study of the } \\
\text { Liver [111] }\end{array}$ & - As per EASL guidelines & $\begin{array}{l}\text { - For the diagnosis of NASH biochemical tests or imaging } \\
\text { techniques cannot distinguish NASH from simple steatosis and } \\
\text { liver biopsy remains the reference standard }\end{array}$ \\
\hline \multicolumn{3}{|c|}{$\begin{array}{l}\text { AASLD: American Association for the Study of Liver Diseases; BARD: body mass index, AST/ALT ratio, and diabetes; BMI: body mass index; CVD: } \\
\text { cardiovascular disease; EASL: European Association for the Study of the Liver; ELF: Enhanced Liver Fibrosis test; FIB-4: Fibrosis-4 score; MetS: metabolic } \\
\text { syndrome; MRE: magnetic resonance elastography; NAFLD: nonalcoholic fatty liver disease; NASH: nonalcoholic steatohepatitis; NFS: nonalcoholic fatty } \\
\text { liver disease score; NICE: National Institute for Health and Care Excellence; T2DM: type } 2 \text { diabetes; US: ultrasound; VCTE: vibration-controlled transient } \\
\text { elastography; WGO: World Gastroenterology Organisation }\end{array}$} \\
\hline
\end{tabular}

Screening at-risk patients has been shown to be costeffective in several studies across different countries [43-45]. With the exception of the current American Association for the Study of Liver Diseases (AASLD) guidelines, most national and international guidelines recommend screening in 'high-risk' populations (Table I). AASLD guidelines recognise obesity and T2DM as two of the most common comorbidities among NASH patients [32], providing motivation towards specifically screening these populations. Until there is more alignment between different guidelines or robust evidence of the benefits of screening the general population, the authors believe that screening at-risk populations is an appropriate starting point for identifying more patients with advanced fibrosis due to NASH.

\section{Key summary points:}

- Screening patients as per current guideline recommendations aims to ensure that those in greatest need will be effectively identified and managed.
- Identifying these patients early through effective screening will link them to care before they develop late-stage liver disease.

- Initiatives are underway to investigate the effectiveness of screening in both the general and at-risk populations.

- The authors believe that avoiding the development of late-stage liver disease, particularly in at-risk patients, will be more cost-effective in the long term.

\section{Which screening tests to use?}

Given the limitations of biopsy for widescale screening, the authors believe that NITs should play an increasing role in detecting NASH. The efficacy and accuracy of these techniques have been described previously in several review articles [46-49], so will only be covered briefly here.

Two main types of NIT are used; predictive models and serum biomarkers which use clinical and laboratory data (Table II), and imaging techniques (Table III) which estimate liver stiffness as a potential surrogate of hepatic fibrosis. 
Table II. Combination scores of noninvasive serum biomarkers of liver fibrosis in NAFLD (adapted from Chin et al, 2016) [54]

\begin{tabular}{|c|c|c|c|c|c|c|c|}
\hline Index & Parameters & $\begin{array}{l}\text { Number } \\
\text { of NAFLD } \\
\text { patients }\end{array}$ & $\begin{array}{l}\text { AUROC for } \\
\text { advanced } \\
\text { fibrosis }\end{array}$ & Sensitivity & Specificity & NPV & PPV \\
\hline $\begin{array}{l}\text { AST/ALT ratio } \\
{[112]}\end{array}$ & AST, ALT & 145 & 0.83 & 74 & 78 & 93 & 44 \\
\hline BARD [113-115] & BMI, AST, ALT, DM & $\begin{array}{c}827 \\
145 \\
138 \\
1038\end{array}$ & $\begin{array}{l}0.81 \\
0.77 \\
0.67 \\
0.76\end{array}$ & $\begin{array}{l}- \\
89 \\
51 \\
74\end{array}$ & $\begin{array}{l}- \\
44 \\
77 \\
66\end{array}$ & $\begin{array}{c}- \\
95 \\
81 \\
-\end{array}$ & $\begin{array}{c}- \\
27 \\
45 \\
-\end{array}$ \\
\hline $\begin{array}{l}\text { FIB-4 } \\
{[112,115,116]}\end{array}$ & Platelet count, AST, ALT, age & $\begin{array}{c}145 \\
541 \\
1038\end{array}$ & $\begin{array}{l}0.86 \\
0.80 \\
0.85\end{array}$ & $\begin{array}{l}85 \\
52 \\
84\end{array}$ & $\begin{array}{l}65 \\
90 \\
69\end{array}$ & $\begin{array}{l}95 \\
- \\
-\end{array}$ & $\begin{array}{l}36 \\
- \\
-\end{array}$ \\
\hline FibroMeter [117] & $\begin{array}{l}\text { Platelet count, prothrombin } \\
\text { index, AST, a2-macro- } \\
\text { globulin, hyaluronic acid, } \\
\text { urea, age }\end{array}$ & 383 & $0.89 \dagger$ & $81 \dagger$ & $84 \dagger$ & $77 \dagger$ & $86 \dagger$ \\
\hline FibroTest [118] & $\begin{array}{l}\text { Haptoglobin, a2-macro- } \\
\text { globulin, apolipoprotein A1, } \\
\text { GGT, bilirubin, age, gender }\end{array}$ & 267 & 0.81 & 92 & 71 & 98 & 33 \\
\hline NFS $[53,112,115]$ & $\begin{array}{l}\text { Age, BMI, platelets, AST/ } \\
\text { ALT, albumin, IFG/diabetes }\end{array}$ & $\begin{array}{c}733 \\
145 \\
1038\end{array}$ & $\begin{array}{c}0.82-0.88 \\
0.81 \\
0.84\end{array}$ & $\begin{array}{c}77-82 \\
33-78 \\
77\end{array}$ & $\begin{array}{c}71-77 \\
58-98 \\
70\end{array}$ & $\begin{array}{c}88-93 \\
86-92 \\
-\end{array}$ & $\begin{array}{c}52-56 \\
30-79 \\
-\end{array}$ \\
\hline ELF score $[59,119]$ & $\begin{array}{l}\text { Hyaluronic acid, TIMP-1, } \\
\text { age, MMP-3 }\end{array}$ & $\begin{array}{c}61 \\
192\end{array}$ & $\begin{array}{l}0.87 \\
0.90\end{array}$ & $\begin{array}{l}89 \\
80\end{array}$ & $\begin{array}{l}96 \\
90\end{array}$ & $\begin{array}{l}96 \\
94\end{array}$ & $\begin{array}{l}80 \\
71\end{array}$ \\
\hline APRI score [112] & AST, platelet count & 145 & 0.67 & 27 & 89 & 84 & 37 \\
\hline
\end{tabular}

$\dagger$ Values are for prediction of significant fibrosis. ALT: alanine amino transferase; APRI: AST-to-platelet ratio index; AST: aspartate aminotransferase; AUROC: area under the receiver operating characteristics curve; BMI: body mass index; DM: diabetes mellitus; ELF: Enhanced Liver Fibrosis blood test; FIB-4: Fibrosis-4 score; GGT: $\gamma$-glutamytransferase; IFG: impaired fasting glycemia; MMP: matrix metalloproteinases; NAFLD: nonalcoholic fatty liver disease; NFS: nonalcoholic fatty liver disease fibrosis score; NPV: negative predictive value; PPV: positive predictive value; TIMP: tissue inhibitors of metalloproteinases

Serum biomarkers are readily available and may be able to exclude a large proportion of the population at low risk [50]. Of the simpler models, aspartate aminotransferase/alanine aminotransferase (AST/ALT) ratio, the NAFLD fibrosis score (NFS), Fibrosis-4 (FIB-4) score, the AST-to-platelet ratio index (APRI), and the BARD score (BMI, AST/ALT ratio and T2DM) are the most widely used and have been validated worldwide (Table II) [51-55].

FIB-4 and NFS are particularly promising tools based on readily available variables (Table II), and can be easily calculated using freely available online calculators [53]. Both tools have good negative predictive values and negative likelihood ratios and can reliably and relatively inexpensively exclude advanced fibrosis, thus identifying lower risk patients who do not need secondary care referral. However, although FIB-4 and NFS are effective at excluding advanced fibrosis, as well as predictive of liver outcomes over time [56], they have limited ability in differentiating between earlier stages of fibrosis [57]. The relative risk at earlier stages is unclear [58].

Commercial biomarker panels such as the Enhanced Liver Fibrosis $\left(\right.$ ELF $\left.^{\mathrm{m} M}\right)$ test, FibroTest ${ }^{\varpi}$ (FibroSure ${ }^{\varpi}$ ) and FibroMeter ${ }^{\circledast}$ are also available, though they are more expensive and less widely available than FIB-4 and NFS. ELFTM is a simplified algorithm comprising a number of parameters (Table II), which can distinguish advanced fibrosis $(\geq \mathrm{F} 3)$ with an area under the receiver operating characteristics curve (AUROC) of 0.90 [59]. It may also be a good predictor of liver-related morbidity and mortality [60]. Therefore, in specialist secondary clinics, this technique may be useful in identifying the presence of advanced fibrosis, though the cut-offs need to be adjusted according to age and sex [61].

Several new scoring systems have also reported good accuracy in detecting advanced fibrosis in patients with NASH. These include the FM-fibro index $[62,63]$ an algorithm based on the measurement of serum PRO-C3 (a marker of type III collagen formation), age, presence of diabetes and platelet count (ADAPT) [64]. There is also the NIS4 scoring system [65] and the CA index, which is based on the combination of type IV collagen $7 \mathrm{~S}$ and AST, and is inexpensive and simple to use [66]. Wisteria floribunda agglutinin-positive (WFA+)Mac-2-binding protein (Mac2BP) levels and type 4 collagen $7 \mathrm{~S}$ levels, alone and in combination, have been shown to be useful independent markers for detecting fibrosis in NAFLD [67]. In addition, the Hepamet Fibrosis Score has recently demonstrated superior diagnostic accuracy, compared with FIB-4 and NFS, in a multinational cohort of 1500 patients [68-70].

Biomarkers and scoring systems are not available universally and this is an important consideration before implementation. Differences in ethnicity can also impact NITs, as FIB-4 and NFS have been shown to perform less well in South Asians compared with Caucasians [71].

In addition to the biomarkers and scoring systems, there are imaging techniques such as magnetic resonance elastography and transient elastography (FibroScan ${ }^{\circledR}$ ) (Table III) [72-74]. FibroScan ${ }^{\circledR}$ has good diagnostic accuracy for the presence of fibrosis $(\geq F 1)$ and advanced fibrosis $(\geq F 3)$, with AUROC of 0.93 for both [75-77]. Its high negative predictive value makes 
Table III. Features of imaging biomarkers (adapted from Wong et al, 2018 [78])

\begin{tabular}{|c|c|c|c|c|c|}
\hline Test & Description & AUROC & Reproducibility & Feasibility & Limitations \\
\hline USG & $\begin{array}{l}\text { The echogenicity, or } \\
\text { brightness, of tissue } \\
\text { depends on the degree } \\
\text { of beam scattering by } \\
\text { the tissue (fat deposition } \\
\text { in tissue accentuates } \\
\text { scattering) advanced } \\
\text { fibrosis }\end{array}$ & $\begin{array}{l}0.93 \text { for diagnosis of } \\
\text { steatosis }(\text { Sn } 60-80 \% \text {, } \\
\text { Sp } 80-100 \%)\end{array}$ & $\begin{array}{l}\text { Reliability: kappa } \\
\text { statistics ranging } \\
\text { from } 0.54 \text { to } 0.92 \text { for } \\
\text { intrarater reliability } \\
\text { and from } 0.44 \text { to } 1.00 \\
\text { for interrater reliability }\end{array}$ & $\begin{array}{l}\text { - Easy to perform and } \\
\text { interpret } \\
\text { - No radiation } \\
\text { - Available in extremely } \\
\text { high numbers across } \\
\text { medical centres across the } \\
\text { world } \\
\text { - Low cost }\end{array}$ & $\begin{array}{l}\text { - Low sensitivity for mild } \\
\text { steatosis } \\
\text { - Operator-dependent } \\
\text { - Reduction of Sn and Sp } \\
\text { in patients who are obese } \\
\text { and those with advanced } \\
\text { fibrosis }\end{array}$ \\
\hline $\begin{array}{l}\text { Controlled } \\
\text { attenuation } \\
\text { parameter }\end{array}$ & $\begin{array}{l}\text { Measurement of the } \\
\text { degree of ultrasound } \\
\text { attenuation by hepatic fat } \\
\text { using a process based on } \\
\text { simultaneous TE }\end{array}$ & $\begin{array}{l}0.82 \text { for diagnosing } \\
\text { any steatosis (Sn } 69 \% \text {, } \\
\text { Sp } 82 \% \text { ) } \\
0.86 \text { for diagnosing } \\
\text { stage } 2 \text { and stage } 3 \\
\text { steatosis (Sn } 77 \% \text {, } \\
\text { Sp } 81 \% \text { ) } \\
0.88 \text { for diagnosing } \\
\text { stage } 3 \text { steatosis (Sn } \\
88 \%, \text { Sp } 78 \% \text { ) }\end{array}$ & $\begin{array}{l}\text { Concordance } \\
\text { correlation coefficient } \\
0.82\end{array}$ & $\begin{array}{l}\text { - Immediate assessment } \\
\text { of steatosis } \\
\text { - Ambulatory clinic } \\
\text { setting } \\
\text { - Simultaneous liver } \\
\text { stiffness measurement } \\
\text { - Failure rate }<10 \%\end{array}$ & $\begin{array}{l}\text { - Does not reliably } \\
\text { differentiate between } \\
\text { steatosis grades }\end{array}$ \\
\hline MRI-PDFF & $\begin{array}{l}\text { PDFF measurement is } \\
\text { an option that can be } \\
\text { added to MRI scanners } \\
\text { to quantitatively assess } \\
\text { steatosis }\end{array}$ & $\begin{array}{l}\text { AUROC } 0.99 \text { for } \\
\text { diagnosing any } \\
\text { steatosis (Sn 96\%, Sp } \\
100 \%, \text { PPV 1.00, NPV } \\
0.70)\end{array}$ & ICC $>0.90$ & $\begin{array}{l}\text { - Not affected by obesity } \\
\text { - Simultaneous MRI for } \\
\text { liver architecture and } \\
\text { carcinoma and MRS for } \\
\text { steatosis }\end{array}$ & $\begin{array}{l}\text { - Costly } \\
\text { - Time consuming } \\
\text { - Requires MRI facility } \\
\text { - Might be inaccurate in } \\
\text { acute inflammation or iron } \\
\text { overload } \\
\text { - Cannot be used in some } \\
\text { patients with implantable } \\
\text { devices }\end{array}$ \\
\hline MRS $\dagger$ & $\begin{array}{l}\text { - Assesses liver triglyceride } \\
\text { content } \\
\text { - Provides a collection } \\
\text { of spectra for signal } \\
\text { fat fraction estimation, } \\
\text { which requires a proper } \\
\text { acquisition technique in } \\
\text { order to estimate the fat }\end{array}$ & $\begin{array}{l}\text { - Sn } 89 \% \text { and } S p 92 \% \\
\text { for diagnosis of liver } \\
\text { fat with a threshold of } \\
0-5 \% \text { fat } \\
\text { - Sn } 83 \% \text { and } S p 94 \% \\
\text { for diagnosis of } 10 \% \\
\text { liver fat } \\
\text { - Sn } 73 \% \text { and Sp } 96 \% \\
\text { for diagnosis of liver } \\
\text { fat }>30 \%\end{array}$ & $\begin{array}{l}\text { Very high with } \\
\text { ICC } 99.8 \%\end{array}$ & $\begin{array}{l}\text { - The absolute liver fat } \\
\text { concentration can be } \\
\text { directly measured, and } \\
\text { very small amounts of } \\
\text { liver fat (as low as } 0.5 \% \text { ) } \\
\text { can be detected and } \\
\text { quantified }\end{array}$ & $\begin{array}{l}\text { - Complex and time- } \\
\text { consuming data analysis } \\
\text { - Data collection occurs } \\
\text { from a small portion of } \\
\text { the liver (within a voxel } \\
\leq 3 \mathrm{~cm} \times 3 \mathrm{~cm} \times 3 \mathrm{~cm} \text { ), } \\
\text { which might be subject to } \\
\text { sampling error }\end{array}$ \\
\hline
\end{tabular}

$\dagger$ AUROC not available. AUROC: area under the receiver operating characteristics curve; ICC: intraclass correlation coefficient; MRI: magnetic resonance imaging; MRS: magnetic resonance spectroscopy; NPV: negative predictive value; PDFF: proton density fat fraction; PPV: positive predictive value; Sn: sensitivity; Sp: specificity; TE: transient elastography; USG: ultrasonography

it a useful screening tool to rule out the presence of fibrosis and differentiate between early and advanced fibrosis [57], but its positive predictive value for ruling in advanced fibrosis or cirrhosis is modest [78].

Other imaging techniques include acoustic radiation force impulse (ARFI), which combines elastography and conventional B-mode ultrasonography to measure liver stiffness [79]. Techniques that use shear wave elastography (SWE) technique have demonstrated significant correlation with histologic scores [80] and can assess liver stiffness by measuring the velocity of elastic shear waves in the liver parenchyma [81]. Two-dimensional SWE shows promise in the non-invasive staging of liver fibrosis in patients with NAFLD, although cut-offs need to be optimised [82]. Additionally, there is the LiverMultiScanTM which uses multiparametric MRI to provide quantitative measures of liver fat, iron, fibrosis and inflammation [83] and the DeMILI ${ }^{\bullet}$ (Detection of MetabolicInduced Liver Injury) software, which can detect NASH and predict significant fibrosis [84]. Both the LiverMultiScanTM and DeMILI have been utilised in the Liver Investigation: Testing Marker Utility in Steatohepatitis (LITMUS) project, which aims to develop and validate qualification biomarkers that diagnose and/or monitor NAFLD/NASH progression and fibrosis stage [85].

Despite the advances in imaging techniques, these technologies are not routinely available in primary care and are more often used once a suspicion of NASH-related fibrosis has been identified through predictive models and serum biomarkers. Therefore, their use in large-scale screening may be limited, and may be more applicable in specialist secondary care clinical settings.

Some studies have also reported that certain tests may be less sensitive or require modification in some populations, such as morbidly obese patients $[86,87]$. Obesity is associated with limited liver ultrasound sensitivity when diagnosing and monitoring changes in hepatic steatosis over time [88]. Using a semiquantitative ultrasonographic scoring system can improve the performance but can be time-consuming [88]. The FibroScan ${ }^{\circledast} \mathrm{XL}$ probe should be used where possible as it has a more sensitive ultrasound transducer and a greater depth of measurement, making it more appropriate for overweight and obese patients [89-91]. The M probe still provides useful information when it is the only option available [91], though its limitations need to be considered for the $5 \%$ of patients 
who fail transient elastography measurements and the $15 \%$ of patients with unreliable results due to obesity [91-94].

Overall, recommendations regarding the most appropriate techniques cannot be made due to their differing availabilities in different countries and clinical settings. However, in the opinion of the authors, the increasing number of well-validated NITs does allow for a small selection to be suggested (with alternatives) which can be applied to most clinical centres.

\section{Key summary points:}

- Currently available NITs, such as predictive models, serum biomarkers and imaging techniques, can be viable alternatives to the invasive liver biopsy.

- Simple, easy-to-use NITs may be more appropriate for large-scale screening and are therefore particularly useful to include in a referral pathway or model of care.

- The authors suggest that NITs can be used as part of a simple strategy to exclude low-risk patients and identify patients at risk of advanced fibrosis due to NASH.

\section{WHAT COULD A SIMPLE PATHWAY FOR IDENTIFYING PATIENTS LOOK LIKE?}

After careful review of the tools available, the authors believe there is an opportunity to develop a simple, widely applicable pathway for identification of patients with NASH, that enables an accepted theory to be put into practice. This pathway should include specific details of the target population and the sequential use of two NITs. For example, the first NIT (usually in primary care or diabetology) should exclude low- risk patients using a readily available, high specificity/negative predictive value NIT (such as FIB-4 or NFS). The second step (in a specialist care setting) should identify high-risk patients for management in liver clinics and return false-positive patients to primary care for regular follow-up.

Several sequential pathways and algorithms to identify or screen for patients with advanced fibrosis due to NASH have already been developed and utilised in clinical practice. However, these pathways have been tailored to be applicable for a national or regional healthcare system. Therefore, we propose the development of a simple pathway which would be adapted to various geographical locations and clinical settings. Although the lack of a prescriptive algorithm could be considered a limitation, we believe the provision of a simple framework for local adaptation is the key to the earlier diagnosis of patients with advanced fibrosis due to NASH.

Fig. 1 shows a simple pathway developed by the authors of this document. The pathway targets screening of patients with features of metabolic syndrome who are at risk of advanced fibrosis due to NASH. This is in line with guideline recommendations to screen this high-risk group [31], which is relatively easy to identify in routine care $[32,95]$.

When a single NIT is used to identify patients, a significant number may have a score between the established cut-offs, suggesting inconclusive results or an indeterminate stage of fibrosis [96]. The sequential use of NITs can reduce rates of secondary and tertiary referrals and achieve greater cost savings compared with single NITs $[97,98]$. In one study, sequential

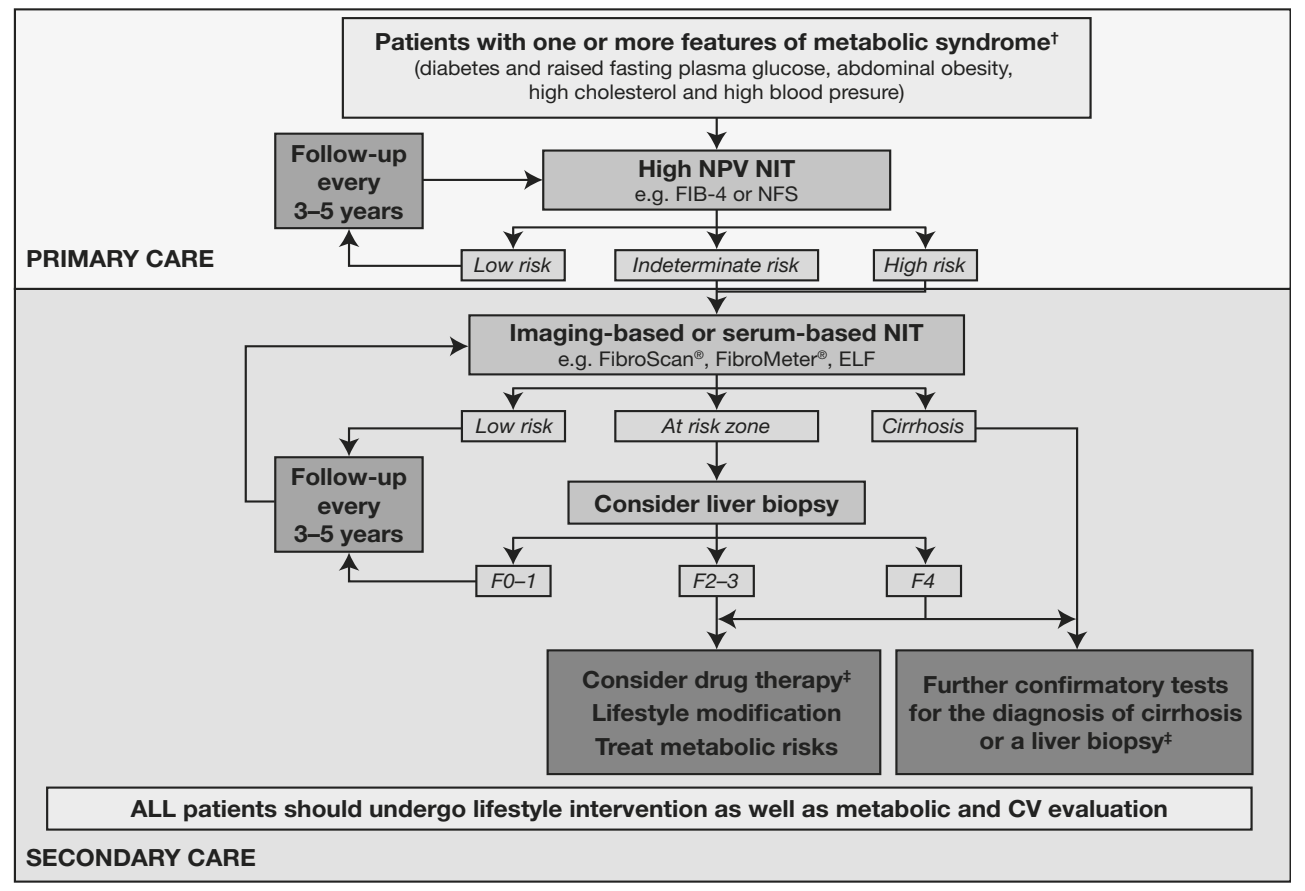

Fig. 1. Proposed testing and referral pathway for the identification and management of patients with advanced fibrosis due to NASH. Due to differences in availability, specific noninvasive tests have only been suggested as examples.

$†$ For further details on metabolic syndrome please refer to the International Diabetes Federation (IDF) consensus worldwide definition of the metabolic syndrome [120]. \$Consider a clinical trial if available. Patients with F4/cirrhosis and hepatic decompensation (Child class B or C) and/or development of HCC who are not candidates for a clinical trial should be referred for liver transplant evaluation. CV: cardiovascular; ELF: enhanced liver fibrosis; F: fibrosis stage; FIB-4: fibrosis-4; HCC: hepatocellular carcinoma; NFS: NAFLD fibrosis score; NIT: noninvasive test; NPV: negative predictive value. 
two-step testing with FIB-4 and ELFTM reduced unnecessary referrals by $80 \%$ and resulted in a 3 -fold improvement in the detection of cirrhosis [99]. Therefore, the authors recommend adopting an algorithm using sequential testing, where intermediate results indicate a second NIT.

The pathway proposed in Fig. 1 includes sequential use of either FIB-4 or NFS, which do not require specialised equipment, can be calculated using online tools and is favoured by treatment guidelines and other published algorithms [31, $32,99-103$ ]. The choice between FIB-4 or NFS can be based on local availability and physician preference. Some data suggest that FIB-4 performs better than NFS in obese patients [100].

If patients present with results indicative of an intermediate or a high risk of advanced fibrosis (i.e. if advanced fibrosis cannot be excluded) following the initial round of scoring/ biomarker testing, they should be referred to secondary/ specialist care. Examples of secondary tests suggested in the proposed pathway that can be carried out in specialist clinics include ELFTM and FibroScan ${ }^{\circledR}$, which are commonly cited secondary tests in other pathways and algorithms [100-104]. FibroScan ${ }^{\circledast}$ in particular is recommended by the AASLD to identify patients with advanced fibrosis [32]. Unlike NFS and FIB-4, FibroScan ${ }^{\circledR}$ measures fibrosis directly and is more applicable to a specialist clinic.

Patients in whom advanced fibrosis cannot be excluded following the secondary test should be considered for liver biopsy, ensuring that only the most uncertain cases are referred for this expensive and invasive procedure. Patients at high risk of NASH cirrhosis should also be considered for HCC surveillance (using ultrasound) and variceal screening (using FibroScan ${ }^{\circledast}$ ) with the Baveno VI criteria [104-106]. Following secondary testing, patients with significant or advanced fibrosis should be monitored every 1-2 years, or every $3-5$ years for those at low risk of advanced fibrosis.

The proposed pathway focuses on hepatology. We acknowledge that for it to be effective, engagement with HCPs from different medical disciplines is critical. How to achieve this is not always clear and will vary between countries. In addition, knowledge around the natural history of NASH continues to expand and the cost-effectiveness of screening will change when effective treatments for NASH become available; researchers should provide updated information to guide practice.

\section{Key summary points}

- A simple pathway has been developed to encourage HCPs to screen and identify patients with advanced fibrosis due to NASH (Figure 1).

- Use of a pathway that includes sequential use of NITs, ideally with the use of a biological marker and an imaging technique, is recommended.

- The pathway should be tried in different settings and modified according to local needs.

- The pathway should be refined regularly based on the latest knowledge to provide up-to-date guidance for practice.

\section{CONCLUSIONS}

NASH-related fibrosis represents a major and increasing public health issue which is largely under-recognised. Fast, simple and accessible NITs such as FIB-4, NFS, FibroScan ${ }^{\circledR}$ and ELF may provide an opportunity to ensure early identification of patients with advanced fibrosis due to NASH. We believe that the adoption of a simple pathway as described in this manuscript should help to educate HCPs (both in primary and secondary care) on the importance of screening for advanced fibrosis due to NASH. This will be essential if the associated burden is to be ameliorated.

Conflicts of interest: S.A. has served as a speaker for Gilead Sciences, Menarini, MSD and Novartis; a consultant for Ferrer, Gilead Sciences, Intercept, IQVIA, Novartis and Pfizer; an advisory board member for Gilead Sciences, Intercept, IQVIA, Novartis and Pfizer; and has received research funding from Gilead Sciences. A.A. has served as a consultant and advisory board member for Gilead Sciences and Intercept and has received research funding from Gilead Sciences and Intercept. N.A. has served as a speaker for AbbVie, Alexion, Allergan, Eisai, Exelixis Intercept and Salix; a consultant for Allergan, Gilead Sciences and Intercept; and has received research funding from Ackero, Albireo, Allergan, Boehringer Ingelheim, Bristol-Myers Squibb, Galmed, Genfit, Gilead Sciences, Intercept, Madrigal, MedImmune, Novartis, Novo Nordisk, Pfizer, Poxel and Zydus. A.C. has served as a speaker for Gilead Sciences, Shire, Falk-Foundation, AbbVie, Novartis and Alexion. L.C. has served as a speaker for Janssen; an advisory board member for Gilead Sciences, Intercept and Norgine; and has received research funding from AbbVie. A.N. has served as a consultant for EA Pharma Co. Ltd. T.O. has served as an advisory board member for Gilead Sciences Ltd. S.P. has served as a speaker and/or advisory board member for AbbVie, Gilead Sciences and Intercept. V.R. has served as a consultant for Allergan, Boehringer, Bristol Myers Squibb, Galmed, GENFIT, Intercept and Pfizer. E.A.T. has served as a speaker for Gilead Sciences and Intercept and an advisory board member for Gilead Sciences, Intercept, Pfizer and Promethera. V.W.S.W. has served as a speaker for Bristol-Myers Squibb, Echosens, Gilead Sciences and Merck; a consultant and/or advisory board member for 3V-BIO, AbbVie, Allergan, Boehringer Ingelheim, Center for Outcomes Research in Liver Diseases, Echosens, Gilead Sciences, Intercept, Janssen, Novartis, Novo Nordisk, Perspectum Diagnostics, Pfizer, TARGET-NASH and Terns; and has received research funding and served as an advisor for Gilead Sciences. M.R.G has served as a speaker for AbbVie, Bristol-Myers Squibb, GENFIT, Gilead Sciences, Intercept, MSD and Roche; an advisory board member for GENFIT, Gilead Sciences, Intercept, Janssen-Cilag, Kaleido, NovoNordisk, Medimmune and Prosceinto; has received research grants from Abbvie, Gilead Sciences and Intercept; and co-owns DeMILI (noninvasive magnetic resonance-based method for diagnosing nonalcoholic steatohepatitis).

Authors' contribution: All authors made substantial contributions to the conception of this work and all were involved in critically reviewing and revising each draft for important intellectual content. All authors have approved the final submitted version and agree to be accountable for all aspects of the work. Guarantor of article: Professor Manuel Romero-Gómez takes responsibility for the integrity of the work as a whole, from inception to published article.

Acknowledgements: Medical writing support was provided by Helen Davies and Selene Jarrett of Elements Communications Ltd and funded by Gilead Sciences Europe Ltd. 


\section{REFERENCES}

1. Marcellin P, Kutala BK. Liver diseases: A major, neglected global public health problem requiring urgent actions and large-scale screening. Liver Int 2018;38(Suppl 1):2-6. doi:10.1111/liv.13682

2. Younossi ZM. Non-alcoholic fatty liver disease - A global public health perspective. J Hepatol 2019;70:531-544. doi:10.1016/j.jhep.2018.10.033

3. Karlsen TH, Tacke F. «The times they are a'changin'» - Positioning the European Association for the Study of the Liver in the changing landscape of hepatology. J Hepatol 2018;68:873-875. doi:10.1016/j. jhep.2018.02.001

4. Younossi ZM, Koenig AB, Abdelatif D, Fazel Y, Henry L, Wymer M. Global epidemiology of nonalcoholic fatty liver disease-Meta-analytic assessment of prevalence, incidence, and outcomes. Hepatology 2016;64:73-84. doi:10.1002/hep.28431

5. Diehl AM, Day C. Cause, pathogenesis, and treatment of nonalcoholic steatohepatitis. N Engl J Med 2017;377:2063-2072. doi:10.1056/ NEJMra1503519

6. Estes C, Anstee QM, Arias-Loste MT, et al. Modeling NAFLD disease burden in China, France, Germany, Italy, Japan, Spain, United Kingdom, and United States for the period 2016-2030. J Hepatol 2018;69:896-904. doi:10.1016/j.jhep.2018.05.036

7. Kabbany MN, Conjeevaram Selvakumar PK, Watt K, et al. Prevalence of nonalcoholic steatohepatitis-associated cirrhosis in the United States: An analysis of National Health and Nutrition Examination Survey Data. Am J Gastroenterol 2017;112:581-587. doi:10.1038/ajg.2017.5

8. Noureddin M, Vipani A, Bresee C, et al. NASH leading cause of liver transplant in women: Updated analysis of indications for liver transplant and ethnic and gender variances. Am J Gastroenterol 2018;113:16491659. doi:10.1038/s41395-018-0088-6

9. Younossi Z, Stepanova M, Ong JP, et al. Nonalcoholic steatohepatitis is the fastest growing cause of hepatocellular carcinoma in liver transplant candidates. Clin Gastroenterol Hepatol 2019;17:748-755. e3. doi:10.1016/j.cgh.2018.05.057

10. Than NN, Ghazanfar A, Hodson J, et al. Comparing clinical presentations, treatments and outcomes of hepatocellular carcinoma due to hepatitis $\mathrm{C}$ and non-alcoholic fatty liver disease. QJM 2017;110:73-81. doi:10.1093/ qjmed/hcw 151

11. Younossi ZM, Blissett D, Blissett R, et al. The economic and clinical burden of nonalcoholic fatty liver disease in the United States and Europe. Hepatology 2016;64:1577-1586. doi:10.1002/hep.28785

12. Byrne CD, Targher G. NAFLD: A multisystem disease. J Hepatol 2015;62(1 Suppl):S47-S64. doi:10.1016/j.jhep.2014.12.012

13. Ahn JS, Sinn DH, Min YW, et al. Non-alcoholic fatty liver diseases and risk of colorectal neoplasia. Aliment Pharmacol Ther 2017;45:345-353. doi:10.1111/apt.13866

14. Targher G, Bertolini L, Padovani R, et al. Prevalence of nonalcoholic fatty liver disease and its association with cardiovascular disease among type 2 diabetic patients. Diabetes Care 2007;30:1212-1218. doi:10.2337/ dc06-2247

15. Kwok R, Choi KC, Wong GL, et al. Screening diabetic patients for non-alcoholic fatty liver disease with controlled attenuation parameter and liver stiffness measurements: a prospective cohort study. Gut 2016;65:1359-1368. doi:10.1136/gutjnl-2015-309265

16. Bril F, Cusi K. Management of nonalcoholic fatty liver disease in patients with type 2 diabetes: A call to action. Diabetes Care 2017;40:419-430. doi:10.2337/dc16-1787

17. Singh S, Allen AM, Wang Z, Prokop LJ, Murad MH, Loomba R. Fibrosis progression in nonalcoholic fatty liver vs nonalcoholic steatohepatitis: a systematic review and meta-analysis of paired-biopsy studies. Clin Gastroenterol Hepatol 2015;13:643-654.e1-e9. doi:10.1016/j. cgh.2014.04.014

18. McPherson S, Hardy T, Henderson E, Burt AD, Day CP, Anstee QM. Evidence of NAFLD progression from steatosis to fibrosingsteatohepatitis using paired biopsies: implications for prognosis and clinical management. J Hepatol 2015;62:1148-1155. doi:10.1016/j. jhep.2014.11.034

19. Dulai PS, Singh S, Patel J, et al. Increased risk of mortality by fibrosis stage in non-alcoholic fatty liver disease: Systematic Review and Metaanalysis. Hepatology 2017;65:1557-1565. doi:10.1002/hep.29085

20. Ekstedt M, Hagström H, Nasr P, et al. Fibrosis stage is the strongest predictor for disease-specific mortality in NAFLD after up to 33 years of follow-up. Hepatology 2015;61:1547-1554. doi:10.1002/hep.27368

21. Angulo P, Kleiner DE, Dam-Larsen S, et al. Liver fibrosis, but no other histologic features, is associated with long-term outcomes of patients with nonalcoholic fatty liver disease. Gastroenterology 2015;149:389_ 397.e10. doi:10.1053/j.gastro.2015.04.043

22. Hagström H, Nasr P, Ekstedt M, et al. Fibrosis stage but not NASH predicts mortality and time to development of severe liver disease in biopsy-proven NAFLD. J Hepatol 2017;67:1265-1273. doi:10.1016/j. jhep.2017.07.027

23. VanWagner LB, Rinella ME. Extrahepatic manifestations of nonalcoholic fatty liver disease. Curr Hepatol Rep 2016;15:75-85. doi:10.1007/s11901-016-0295-9

24. Portillo-Sanchez P, Bril F, Maximos M, et al. High prevalence of nonalcoholic fatty liver disease in patients with type 2 diabetes mellitus and normal plasma aminotransferase levels. J Clin Endocrinol Metab 2015;100:2231-2238. doi:10.1210/jc.2015-1966

25. Bertot LC, Jeffrey GP, Wallace M, et al. Nonalcoholic fatty liver diseaserelated cirrhosis is commonly unrecognized and associated with hepatocellular carcinoma. Hepatol Commun 2017;1:53-60. doi:10.1002/ hep4.1018

26. Nagpal SJ, Kabbany MN, Mohamad B, Lopez R, Zein NN, Alkhouri N. Portal hypertension complications are frequently the first presentation of NAFLD in patients undergoing liver transplantation evaluation. Dig Dis Sci 2016;61:2102-2107. doi:10.1007/s10620-016-4124-3

27. Ginès $\mathrm{P}$, Graupera I, Lammert $\mathrm{F}$, et al. Screening for liver fibrosis in the general population: a call for action. Lancet Gastroenterol Hepatol 2016;1:256-260. doi:10.1016/S2468-1253(16)30081-4

28. Polanco-Briceno S, Glass D, Stuntz M, Caze A. Awareness of nonalcoholic steatohepatitis and associated practice patterns of primary care physicians and specialists. BMC Res Notes 2016;9:157. doi:10.1186/ s13104-016-1946-1

29. Patel PJ, Banh X, Horsfall LU, et al. Underappreciation of non-alcoholic fatty liver disease by primary care clinicians: limited awareness of surrogate markers of fibrosis. Intern Med J 2018;48:144-151. doi:10.1111/imj.13667

30. Bergqvist CJ, Skoien R, Horsfall L, Clouston AD, Jonsson JR, Powell EE. Awareness and opinions on non-alcoholic fatty liver disease by hospital specialists. Intern Med J 2013;43:247-253. doi:10.1111/j.14455994.2012.02848.x

31. European Association for the Study of the Liver (EASL); European Association for the Study of Diabetes (EASD); European Association for the Study of Obesity (EASO). EASL-EASD-EASO Clinical Practice Guidelines for the management of non-alcoholic fatty liver disease. J Hepatol 2016;64:1388-1402. doi:10.1016/j.jhep.2015.11.004

32. Chalasani N, Younossi Z, Lavine JE, et al. The diagnosis and management of nonalcoholic fatty liver disease: Practice guidance from 
the American Association for the Study of Liver Diseases. Hepatology 2018;67:328-357. doi:10.1002/hep.29367

33. Sumida Y, Nakajima A, Itoh Y. Limitations of liver biopsy and noninvasive diagnostic tests for the diagnosis of nonalcoholic fatty liver disease/nonalcoholic steatohepatitis. World J Gastroenterol 2014;20:475-485. doi:10.3748/wjg.v20.i2.475

34. Vuppalanchi R, Sanyal AJ. Myths and mysteries about staging hepatic fibrosis by fibroscan. Clin Gastroenterol Hepatol 2015;13:780-782. doi:10.1016/j.cgh.2014.10.030

35. Sheridan DA, Aithal G, Alazawi W, et al. Care standards for nonalcoholic fatty liver disease in the United Kingdom 2016: A crosssectional survey. Frontline Gastroenterol 2017;8:252-259. doi:10.1136/ flgastro-2017-100806

36. Golabi P, Otgonsuren M, Cable R, et al. Non-alcoholic fatty liver disease (NAFLD) is associated with impairment of health related quality of life (HRQOL). Health Qual Life Outcomes 2016;14:18. doi:10.1186/ s12955-016-0420-z

37. Kennedy-Martin T, Bae JP, Paczkowski R, Freeman E. Health-related quality of life burden of nonalcoholic steatohepatitis: a robust pragmatic literature review. J Patient Rep Outcomes 2018;2:28. doi:10.1186/ s41687-018-0052-7

38. Tesfay M, Goldkamp WJ, Neuschwander-Tetri BA. NASH: The emerging most common form of chronic liver disease. Mo Med 2018;115:225-229

39. Madrazo BL. Diagnosis of nonalcoholic steatohepatitis without liver biopsy. Gastroenterol Hepatol (N Y) 2017;13:378-380.

40. Ratziu V, Poynard T. NASH: A hidden and silent fibroser finally revealed? J Hepatol 2005;42:12-14. doi:10.1016/j.jhep.2004.11.027

41. Review Team, LaBrecque DR, Abbas Z, et al. World Gastroenterology Organisation. World Gastroenterology Organisation global guidelines: Nonalcoholic fatty liver disease and nonalcoholic steatohepatitis. J Clin Gastroenterol 2014;48:467-473. doi:10.1097/MCG.0000000000000116

42. Llop E, Iruzubieta P, Perelló C, et al. Transition elastography as a method of screening of chronic hepatic disease in apparently healthy population. Results from ETHON cohort. J Hepatol 2018;68 Suppl 1:S634. doi:10.1016/S0168-8278(18)31525-3

43. Zhang E, Wartelle-Bladou C, Lepanto L, Lachaine J, Cloutier G, Tang A. Cost-utility analysis of nonalcoholic steatohepatitis screening. Eur Radiol 2015;25:3282-3294. doi:10.1007/s00330-015-3731-2

44. Phisalprapa P, Supakankunti S, Charatcharoenwitthaya P, et al. Costeffectiveness analysis of ultrasonography screening for nonalcoholic fatty liver disease in metabolic syndrome patients. Medicine (Baltimore) 2017;96:e6585. doi:10.1097/MD.0000000000006585

45. Tanajewski L, Harris R, Harman DJ, et al. Economic evaluation of a community-based diagnostic pathway to stratify adults for nonalcoholic fatty liver disease: a Markov model informed by a feasibility study. BMJ Open 2017;7:e015659. doi:10.1136/bmjopen-2016-015659

46. Alkhouri N, Feldstein AE. Noninvasive diagnosis of nonalcoholic fatty liver disease: Are we there yet? Metabolism 2016;65:1087-1095. doi:10.1016/j.metabol.2016.01.013

47. Chin JL, Pavlides M, Moolla A, Ryan JD. Non-invasive markers of liver fibrosis: Adjuncts or alternatives to liver biopsy? Front Pharmacol 2016;7:159. doi:10.3389/fphar.2016.00159

48. Jayakumar S, Harrison SA, Loomba R. Noninvasive markers of fibrosis and inflammation in nonalcoholic fatty liver disease. Curr Hepatol Rep 2016;15:86-95. doi:10.1007/s11901-016-0296-8

49. Castéra L, Friedrich R, Loomba R. Noninvasive assessment of liver disease in patients with nonalcoholic fatty liver disease. Gastroenterology 2019;156:1264-1281.e4. doi:10.1053/j.gastro.2018.12.036
50. Castéra L. Diagnosis of non-alcoholic fatty liver disease/non-alcoholic steatohepatitis: Non-invasive tests are enough. Liver Int 2018;38 Suppl 1:67-70. doi:10.1111/liv.13658

51. Dyson JK, Anstee QM, McPherson S. Non-alcoholic fatty liver disease: a practical approach to diagnosis and staging. Frontline Gastroenterol 2014;5:211-221.

52. Angulo P, Hui JM, Marchesini G, et al. The NAFLD fibrosis score: a noninvasive system that identifies liver fibrosis in patients with NAFLD. Hepatology 2007;45:846-854. doi:10.1002/hep.21496

53. Sterling RK, Lissen E, Clumeck N, et al. APRICOT Clinical Investigators. Development of a simple noninvasive index to predict significant fibrosis in patients with HIV/HCV coinfection. Hepatology 2006;43:1317-1325. doi:10.1002/hep. 21178

54. McPherson S, Anstee QM, Henderson E, Day CP, Burt AD. Are simple noninvasive scoring systems for fibrosis reliable in patients with NAFLD and normal ALT levels? Eur J Gastroenterol Hepatol 2013;25:652-658. doi:10.1097/MEG.0b013e32835d72cf

55. Cichoż-Lach H, Celiński K, Prozorow-Król B, Swatek J, Słomka M, Lach T. The BARD score and the NAFLD fibrosis score in the assessment of advanced liver fibrosis in nonalcoholic fatty liver disease. Med Sci Monit 2012;18:CR735-CR740. doi:10.12659/MSM.883601

56. Angulo P, Bugianesi E, Bjornsson ES, et al. Simple noninvasive systems predict long-term outcomes of patients with nonalcoholic fatty liver disease. Gastroenterology 2013;145:782-789.e4. doi:10.1053/j. gastro.2013.06.057

57. Cheah MC, McCullough AJ, Goh GB. Current modalities of fibrosis assessment in non-alcoholic fatty liver. J Clin Transl Hepatol 2017;5:261-271. doi:10.14218/JCTH.2017.00009

58. Ratziu V. Back to Byzance: Querelles byzantines over NASH and fibrosis. J Hepatol 2017;67:1134-1136. doi:10.1016/j.jhep.2017.09.024

59. Guha IN, Parkes J, Roderick P, et al. Noninvasive markers of fibrosis in nonalcoholic fatty liver disease: Validating the European Liver Fibrosis Panel and exploring simple markers. Hepatology 2008;47:455-460. doi:10.1002/hep.21984

60. Parkes J, Roderick P, Harris S, et al. Enhanced liver fibrosis test can predict clinical outcomes in patients with chronic liver disease. Gut 2010;59:1245-1251. doi:10.1136/gut.2009.203166

61. Lichtinghagen R, Pietsch D, Bantel H, Manns MP, Brand K, Bahr MJ. The enhanced liver fibrosis (ELF) score: normal values, influence factors and proposed cut-off values. J Hepatol 2013;59:236-242. doi:10.1016/j. jhep.2013.03.016

62. Itoh $\mathrm{Y}$, Seko $\mathrm{Y}$, Shima $\mathrm{T}$, et al. Accuracy of non-invasive scoring systems for diagnosing non-alcoholic steatohepatitis-related fibrosis: Multicenter validation study. Hepatol Res 2018;48:1099-1107. doi:10.1111/hepr.13226

63. Yoshimura $\mathrm{K}$, Okanoue $\mathrm{T}$, Ebise $\mathrm{H}$, et al. Identification of novel noninvasive markers for diagnosis nonalcoholic steatohepatitis and related fibrosis by data mining. Hepatology 2016;63:462-473. doi:10.1002/hep.28226

64. Daniels SJ, Leeming DJ, Eslam M, et al. ADAPT: An algorithm incorporating PRO-C3 accurately identifies patients with NAFLD and advanced fibrosis. Hepatology 2019;69:1075-1086. doi:10.1002/ hep. 30163

65. Hanf R, Harrison SA, Bedossa P, et al. NIS4 for detection of active NASH (NAS $\geq 4$ ) and significant fibrosis $(\mathrm{F} \geq 2)$ in 714 patients at risk of NASH: diagnostic metrics are not affected by age, gender, type 2 diabetes or obesity. Presented at: the Annual Meeting of the American Association for the Study of Liver Diseases, 2018, San Francisco, CA 2018. 
66. Okanoue T, Ebise H, Kai T, et al. A simple scoring system using type IV collagen $7 \mathrm{~S}$ and aspartate aminotransferase for diagnosing nonalcoholic steatohepatitis and related fibrosis. J Gastroenterol 2018;53:129-139. doi:10.1007/s00535-017-1355-9

67. Ogawa Y, Honda Y, Kessoku T, et al. Wisteria floribunda agglutininpositive Mac-2-binding protein and type 4 collagen 7S: useful markers for the diagnosis of significant fibrosis in patients with non-alcoholic fatty liver disease. J Gastroenterol Hepatol 2018;33:1795-1803. doi:10.1111/jgh.14156

68. Ampuero J, Aller R, Gallego-Durán R, et al. Clinical Outcomes in biopsy-proven NAFLD patients from the HEPAmet Spanish Registry. J Hepatol 2018;68(Suppl 1):S833. doi:10.1016/S0168-8278(18)31942-1

69. Ampuero J, Aller R, Gallego-Durán R, et al. Hepamet Score: a new non-invasive method for NAFLD-related fibrosis screening in clinical practice. J Hepatol 2018;68(Suppl 1):S97-S98. doi:10.1016/S01688278(18)30415-X

70. Ampuero J, Pais R, Aller R, et al. Development and Validation of Hepamet Fibrosis Scoring System-A Simple, Noninvasive Test to Identify Patients With Nonalcoholic Fatty Liver Disease With Advanced Fibrosis. Clin Gastroenterol Hepatol 2020;18:216-225. doi:10.1016/j. cgh.2019.05.051

71. De Silva S, Li W, Kemos P, et al. Non-invasive markers of liver fibrosis in fatty liver disease are unreliable in people of South Asian descent. Frontline Gastroenterol 2018;9:115-121. doi:10.1136/ flgastro-2017-100865

72. Dulai PS, Sirlin CB, Loomba R. MRI and MRE for non-invasive quantitative assessment of hepatic steatosis and fibrosis in NAFLD and NASH: Clinical trials to clinical practice. J Hepatol 2016;65:1006-1016. doi:10.1016/j.jhep.2016.06.005

73. Coco B, Oliveri F, Maina AM, et al. Transient elastography: a new surrogate marker of liver fibrosis influenced by major changes of transaminases. J Viral Hepat 2007;14:360-369. doi:10.1111/j.13652893.2006.00811.x

74. Afdhal NH. Fibroscan (transient elastography) for the measurement of liver fibrosis. Gastroenterol Hepatol (NY) 2012;8:605-607.

75. Yoneda M, Yoneda M, Fujita K, et al. Transient elastography in patients with non-alcoholic fatty liver disease (NAFLD). Gut 2007;56:1330-1331. doi:10.1136/gut.2007.126417

76. Yoneda M, Yoneda M, Mawatari H, et al. Noninvasive assessment of liver fibrosis by measurement of stiffness in patients with nonalcoholic fatty liver disease (NAFLD). Dig Liver Dis 2008;40:371-378. doi:10.1016/j. dld.2007.10.019

77. Wong VW, Vergniol J, Wong GL, et al. Diagnosis of fibrosis and cirrhosis using liver stiffness measurement in nonalcoholic fatty liver disease. Hepatology 2010;51:454-462. doi:10.1002/hep.23312

78. Wong VW, Adams LA, de Lédinghen V, Wong GL, Sookoian S. Noninvasive biomarkers in NAFLD and NASH - current progress and future promise. Nat Rev Gastroenterol Hepatol 2018;15:461-478. doi:10.1038/s41575-018-0014-9

79. Liu H, Fu J, Hong R, Liu L, Li F. Acoustic radiation force impulse elastography for the non-invasive evaluation of hepatic fibrosis in nonalcoholic fatty liver disease patients: A systematic review \& meta-analysis. PLoS One 2015;10:e0127782. doi:10.1371/journal.pone.0127782

80. Cassinotto C, Lapuyade B, Mouries A, et al. Non-invasive assessment of liver fibrosis with impulse elastography: comparison of supersonic shear imaging with ARFI and FibroScan. J Hepatol 2014;61:550-557. doi:10.1016/j.jhep.2014.04.044

81. Xie LT, Yan CH, Zhao QY, He MN, Jiang TA. Quantitative and noninvasive assessment of chronic liver diseases using two-dimensional shear wave elastography. World J Gastroenterol 2018;24:957-970. doi:10.3748/wjg.v24.i9.957

82. Herrmann E, de Lédinghen V, Cassinotto C, et al. Assessment of biopsyproven liver fibrosis by two-dimensional shear wave elastography: An individual patient data-based meta-analysis. Hepatology 2018;67:260-272. doi:10.1002/hep.29179

83. McDonald N, Eddowes PJ, Hodson J, et al. 2018. Multiparametric magnetic resonance imaging for quantitation of liver disease: a two-centre cross-sectional observational study. Sci Rep 2018;8:9189. doi:10.1038/s41598-018-27560-5

84. Gallego-DuránR, Cerro-Salido P, Pareja MJ, et al. P834: Noninvasive management of non-alcoholic fatty liver disease. J Hepatol 2014;60(Supplement):S349-S350. doi: 10.1016/S0168-8278(14)60995-8

85. Anstee QM. LITMUS, EPoS \& the European NAFLD Registry: European efforts to improve the diagnosis of NAFLD. ELPA Stakeholder Meeting on NASH, European Commission, Brussels, Belgium. January 2019.

86. Bertot LC, Jeffrey GP, de Boer B, et al. Diabetes impacts prediction of cirrhosis and prognosis by non-invasive fibrosis models in non-alcoholic fatty liver disease. Liver Int 2018;38:1793-1802. doi:10.1111/liv.13739

87. Drolz A, Wolter S, Wehmeyer M, et al. Performance and reliability of non-invasive fibrosis scores in non-alcoholic fatty liver disease with and without morbid obesity. J Hepatol 2018;68(Suppl 1):S558-S559. doi:10.1016/S0168-8278(18)31374-6

88. Bril F, Ortiz-Lopez C, Lomonaco R, et al. Clinical value of liver ultrasound for the diagnosis of nonalcoholic fatty liver disease in overweight and obese patients. Liver Int 2015;35:2139-2146. doi:10.1111/liv.12840

89. Wong VW, Vergniol J, Wong GL, et al. Liver stiffness measurement using XL probe in patients with nonalcoholic fatty liver disease. Am J Gastroenterol 2012;107:1862-1871. doi:10.1038/ajg.2012.331

90. Durango E, Dietrich C, Seitz HK, et al. Direct comparison of the FibroScan XL and $\mathrm{M}$ probes for assessment of liver fibrosis in obese and nonobese patients. Hepat Med 2013;5:43-52. doi:10.2147/HMER. S45234

91. Sporea I, Șirli R, Mare R, Popescu A, Ivașcu SC. Feasibility of Transient Elastography with $\mathrm{M}$ and XL probes in real life. Med Ultrason 2016;18:7-10.

92. Foucher J, Castéra L, Bernard PH, et al. Prevalence and factors associated with failure of liver stiffness measurement using FibroScan in a prospective study of 2114 examinations. Eur J Gastroenterol Hepatol 2006;18:411-412. doi:10.1097/00042737-200604000-00015

93. Roulot D, Czernichow S, Le Clésiau H, Costes JL, Vergnaud AC, Beaugrand M. Liver stiffness values in apparently healthy subjects: influence of gender and metabolic syndrome. J Hepatol 2008;48:606613. doi:10.1016/j.jhep.2007.11.020

94. Castéra L, Foucher J, Bernard PH, et al. Pitfalls of liver stiffness measurement: a 5-year prospective study of 13,369 examinations. Hepatology 2010;51:828-835. doi:10.1002/hep.23425

95. Mendrick DL, Diehl AM, Topor LS, et al. Metabolic syndrome and associated diseases: From the bench to the clinic. Toxicol Sci 2018;162:36-42. doi:10.1093/toxsci/kfx233

96. Wong VWS, Younossi ZM, Lawitz EJ, et al. IDDF2019. ABS-0131 Algorithms using noninvasive tests can accurately identify patients with advanced fibrosis due to NASH: data from the STELLAR clinical trials. Gut 2019;68(Suppl 1):A135-A136.

97. Majumdar A, Crossan C, Thorburn D, et al. Referral pathways for patients with non-alcoholic fatty liver disease based on non-invasive fibrosis tests: Diagnostic accuracy and cost analysis of a two-tier approach. J Hepatol 2017;66:S51. doi:10.1016/S0168-8278(17)30365-3 
98. Crossan C, Majumdar A, Srivastava A, et al. Referral pathways for patients with NAFLD based on non-invasive fibrosis tests: Diagnostic accuracy and cost analysis. Liver Int 2019;39:2052-2060. doi:10.1111/ liv. 14198

99. Srivastava A, Gailer R, Tanwar S, et al. Prospective evaluation of a primary care referral pathway for patients with non-alcoholic fatty liver disease. J Hepatol 2019;71:371-378. doi:10.1016/j.jhep.2019.03.033

100. Petta S, Wai-Sun Wong V, Bugianesi E, et al. Impact of obesity and alanine aminotransferase levels on the diagnostic accuracy for advanced liver fibrosis of noninvasive tools in patients with NAFLD. Am J Gastroenterol 2019;114:916-928. doi:10.14309/ ajg.0000000000000153

101. Gallacher J, McPherson S. Practical diagnosis and staging of nonalcoholic fatty liver disease: A narrative review. EMJ 2018;3:108118.

102. Tsochatzis EA, Newsome PN. Non-alcoholic fatty liver disease and the interface between primary and secondary care. Lancet Gastroenterol Hepatol 2018;3:509-517. doi:10.1016/S2468-1253(18)30077-3

103. Yoneda M, Imajo K, Nakajima A. Non-Invasive Diagnosis of Nonalcoholic Fatty Liver Disease. Am J Gastroenterol 2018;113:14091411. doi:10.1038/s41395-018-0170-0

104. Augustin S, Pons M, Maurice JB, et al. Expanding the Baveno VI criteria for the screening of varices in patients with compensated advanced chronic liver disease. Hepatology 2017;66:1980-1988. doi:10.1002/ hep. 29363

105. Heimbach JK, Kulik LM, Finn RS, et al. AASLD guidelines for the treatment of hepatocellular carcinoma. Hepatology 2018;67:358-380. doi:10.1002/hep.29086

106. Petta S, Sebastiani G, Bugianesi E, et al. Non-invasive prediction of esophageal varices by stiffness and platelet in non-alcoholic fatty liver disease cirrhosis. J Hepatol 2018;69:878-885. doi:10.1016/j. jhep.2018.05.019

107. Wong VW, Chan WK, Chitturi S, et al. Asia-Pacific Working Party on Non-alcoholic Fatty Liver Disease guidelines 2017-Part 1: Definition, risk factors and assessment. J Gastroenterol Hepatol 2018;33:70-85. doi:10.1111/jgh.13857

108. National Institute for Health and Care Excellence (NICE). Non-alcoholic fatty liver disease (NAFLD): assessment and management. NICE guideline [NG49]. Published: July 6, 2016. Accessed October 29, 2019. Available at: https://www.nice.org.uk/guidance/ng49

109. Watanabe S, Hashimoto E, Ikejima K, et al. Japan Society of Hepatology. Evidence-based clinical practice guidelines for nonalcoholic fatty liver disease/nonalcoholic steatohepatitis. J Gastroenterol 2015;50:364-377. doi:10.1007/s00535-015-1050-7

110. Francque S, Lanthier N, Verbeke L, et al. The Belgian Association for Study of the Liver guidance document on the management of adult and paediatric non-alcoholic fatty liver disease. Acta Gastroenterol Belg 2018;81:55-81.

111. Italian Association for the Study of the Liver (AISF). AISF position paper on nonalcoholic fatty liver disease (NAFLD): Updates and future directions. Dig Liver Dis 2017;49:471-483. doi: 10.1016/j.dld.2017.01.147

112. McPherson S, Stewart SF, Henderson E, Burt AD, Day CP. Simple noninvasive fibrosis scoring systems can reliably exclude advanced fibrosis in patients with non-alcoholic fatty liver disease. Gut 2010;59:12651269. doi:10.1136/gut.2010.216077

113. Harrison SA, Oliver D, Arnold HL, Gogia S, Neuschwander-Tetri BA. Development and validation of a simple NAFLD clinical scoring system for identifying patients without advanced disease. Gut 2008;57:14411447. doi:10.1136/gut.2007.146019

114. Ruffillo G, Fassio E, Alvarez E, et al. Comparison of NAFLD fibrosis score and BARD score in predicting fibrosis in nonalcoholic fatty liver disease. J Hepatol 2011;54:160-163. doi:10.1016/j.jhep.2010.06.028

115. Sun W, Cui H, Li N, et al. Comparison of FIB4 index, NAFLD fibrosis score and BARD score for prediction of advanced fibrosis in adult patients with non-alcoholic fatty liver disease: a meta-analysis study. Hepatol Res 2016;46:862-870. doi:10.1111/hepr.12647

116. Shah AG, Lydecker A, Murray K, Tetri BN, Contos MJ, Sanyal AJ. Comparison of noninvasive markers of fibrosis in patients with nonalcoholic fatty liver disease. Clin Gastroenterol Hepatol 2009;7:1104-1112. doi:10.1016/j.cgh.2009.05.033

117. Calès $\mathrm{P}$, Oberti F, Michalak $\mathrm{S}$, et al. A novel panel of blood markers to assess the degree of liver fibrosis. Hepatology 2005;42:1373-1381. doi:10.1002/hep.20935

118. Ratziu V, Massard J, Charlotte F, et al. Diagnostic value of biochemical markers (FibroTest-FibroSURE) for the prediction of liver fibrosis in patients with non-alcoholic fatty liver disease. BMC Gastroenterol 2006;6:6. doi.10.1186/1471-230X-6-6

119. Rosenberg WM, Voelker M, Thiel R, et al. Serum markers detect the presence of liver fibrosis: a cohort study. Gastroenterology 2004;127:1704-1713. doi:10.1053/j.gastro.2004.08.052

120. International Diabetes Federation (IDF). IDF consensus worldwide definition of the metabolic syndrome. 2006. Accessed October 29, 2019. Available at: https://www.idf.org/e-library/consensus-statements/60idfconsensus-worldwide-definitionof-the-metabolic-syndrome.html 